Analysis of the Carbon and Nitrogen Limitations to Soybean Yield T. R. Sinclair and C. T. de Wit 


\title{
Analysis of the Carbon and Nitrogen Limitations to Soybean Yield ${ }^{1}$
}

\author{
T. R. Sinclair and C. T. de Wit ${ }^{2}$
}

\section{ABSTRACT}

Soybeans are hypothesized to be "self-destructive" since they apparently need to translocate large amounts of nitrogen from vegetative tissues during seed-fill to sustain seed growth. To assess the possible limitations of this characteristic on soybean seed yield, a simple, dynamic simulation model is developed which accounts for the availability of nitrogen and photosynthate within the plant. The simulations show that the duration of seedfill and seed yield is clearly limited by the self-destructive characteristic. Increased availability of nitrogen within the plant is required for significant increases in soybean yields. Possible alterations of the model required to mimic actual soybean seed growth are presented.

Additional index words: Photosynthesis, Nitrogen fixation, Simulation model, Plant self-destruction.

$\mathrm{T}$

$\mathrm{HE}$ increase in commercial soybean yield/land acre of only about $1 \%$ /year has been particularly slow in comparison to advances with most other crops. The ability to increase yields in experimental test plots has also been disappointing and led to the concept that a "yield barrier" may, in fact, exist for soybeans. Questions have been raised about the existence of inherent properties of soybean plants and/or production techniques which prevent substantial yield increases.

In analyzing the photosynthate and nitrogen requirements of seeds, Sinclair and de Wit (1975) found that soybeans are unique among the 24 crop species studied. Having both a high protein and lipid content, soybeans required the highest rate of nitrogen supply to the seed, yet produced biomass at one of the lowest rates. The requirement for nitrogen by the seed was, in fact, found to be so great that in practically all situations nitrogen must be translocated from the vegetative plant tissue to the seed during the seed development period to sustain growth. Since the loss of nitrogen from the vegetative plant could cause a loss of physiological activity and ultimately senescence, we hypothesized that soybeans are "selfdestructive." We further proposed that this selfdestructive characteristic could limit the length of the seed development period and thereby place a potential limit on total seed production. Of course, the effect of the self-destructive characteristic would be dependent on the rate of photosynthate supplied to the seed, rate of external nitrogen supply, and the rate of nitrogen translocation within the plant.

The purpose of this analysis is to examine the poteniial limitation of the self-destructive characteristic on

\footnotetext{
${ }^{1}$ Research supported by the Agricultural Univ., Wageningen, The Netherlands, and in part by the Eastern Deciduous Forest Biome, US-IBP, funded by the National Science Foundation under meragency Agreement AG 199, BMS - 69-01147 A09 with the Energy Research and Development Administration - Oak Ridge National Laboratory. Contribution No. 246 from the Ridge National Laboratory. Contribution No. 246 from the
Eastern Deciduous Forest Biome, US-IBP. Received 11 June 1975. ${ }^{2}$ Plant physiologist, Northeastern Region, ARS-USDA, Cornell Univ., Ithaca, NY and agronomist, Dept. of Theoretical Production Ecology, Agricultural Univ., Wageningen, The Netherlands.
}

soybean seed yield. Only the effect of the carbon and nitrogen allocation during the seed development stage are considered. We assume implicity that the vegetative stage of plant growth limits seed yield only to the extent that the amount of vegetative plant tissues are restrictive in supporting seed development. The model of seed development contains two major features: (a) that the rate of seed growth is determined by the amount of available photosynthate and (b) that the duration of the seed development period is limited by the self-destructive characteristic. In the simulations performed with this model the state variables are defined to correspond to a soybean crop. However our intentions are not to mimic soybean production but rather to assess the potential significance of the availability of carbon and nitrogen on seed yield. Nevertheless we found that manipulation of relatively few variables in the model did produce results which correspond to experimental observations.

\section{METHODS}

\section{Photosynthate Availability}

The ability of plants to fix atmospheric $\mathrm{CO}_{2}$ into carbohydrate places the initial restriction on yield. Because we assume that carbon translocated within the plants contribute insignificantly to seed development, the rate of seed production is no greater than the current rate of material produced by photosynthesis. This apparent, direct limitation of photosynthetic rate on seed yield has led to several attempts to identify soybean genotypes with high rates of $\mathrm{CO}_{2}$ assimilation (Curtis et al., 1969; Dreger et al., 1969; and Dornhoff and Shibles, 1970). A reasonably wide range has been observed for individual leaves at saturating irradiances. Therefore our first set of calculations estimates the availability of photosynthate for varying $\mathrm{CO}_{2}$ assimilation rates of individual leaves.

Total, or more commonly gross, daily photosynthetic rates of soybean crops are calculated from four leaf $\mathrm{CO}_{2}$ assimilationlight response curves. The response of individual leaves observed by Bowes et al. (1972) for the cultivar 'Wayne' grown in the field under different degrees of shading yielded net $\mathrm{CO}_{2}$ assimilation rates at saturating irradiances of $30 \mathrm{mg} \mathrm{CO} \cdot \mathrm{dm}^{-2} \cdot \mathrm{h}^{-1}$ for plants grown under $70 \%$ shade, $\mathrm{D}$, and about $45 \mathrm{mg}$ $\mathrm{CO}_{2} \cdot \mathrm{dm}^{-2} \cdot \mathrm{h}^{-1}$ for plants that were unshaded, A. The gross photosynthate rates of the individual leaves shown in Fig. 1

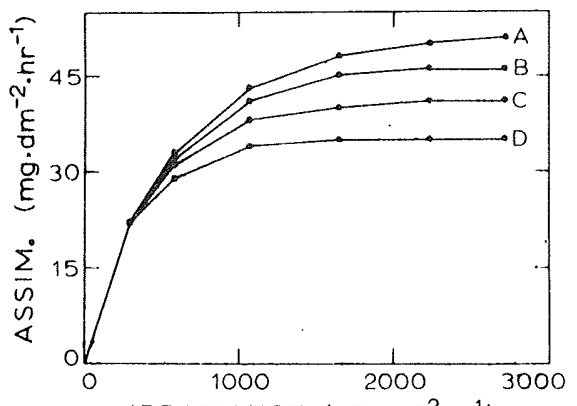

Fig. 1. Simulated light response curves of gross $\mathrm{CO}_{3}$ assimilation by soybean leaves grown under unshaded (A), 30\% shaded (B), $50 \%$ shaded $(\mathrm{C})$, and $70 \%$ shaded $(\mathrm{D})$ conditions. These responses were derived from data presented by Bowes et al. (1972). 
are ohtained by adding $5 \mathrm{mg} \cdot \mathrm{dm}^{-2} \cdot \mathrm{h}^{-1}$ as an estimate of respiratint to the data of Bowes et al.

Computation of the daily $\mathrm{CO}_{2}$ assimilation rates of a whole crop canopy based on irradiance responses of individual leaves leyuires consideration of changes in the solar altitude, varialions in relative amounts of diffuse and direct radiation, and distribution of the radiation in the leaf canopy. The radiation penetration molel developed by Goudriaan (1973) is used to calculate the datiation distribution on laves. This model as. sumes a tathdom spatial distribution of leaves and calculates the radiation distribution in the leaf canopy as a function of the inclination of the incident radiation and the leaf angle distribution. The solar inclination is calculated as a function of time while inclination of the incident diffuse radiation is calculated by assuming the radiation originated from a uniformly illuminated sky. The leaf angle distribution for soybeans, obtained from the data presented by Blad and Baker (1972), is used to calculate both the interception of radiation and the irradiance on individual leaf segments. The crop $\mathrm{CO}_{2}$ assimilation rate is calculated at half hour intervals and then integrated to provide the estimate of daily, gross $\mathrm{CO}_{2}$ assimilation. The $\mathrm{CO}_{2}$ assimilation of crops of leaf area indices (LAI) of $0.8,0.6$, $1.0,1.5,2.0,2.5,3.0,4.0$, and 6.0 are computed for each of the four leaf assimilation rates.

These estimates of crop $\mathrm{CO}_{2}$ assimilation rates are multiplied by the ratio of the molecular weight of $\mathrm{CH}_{2} \mathrm{O}$ to $\mathrm{CO}_{2}$ to obtain the daily gross photosynthate productivity presented in Fig. 2. As expected the crops with the greater LAI and leaf $\mathrm{CO}_{2}$ assimilation rates produce the most photosynthate. However the differences among the crop $\mathrm{CO}_{2}$ assimilation rates are not as great as among the light saturated assimilation rates of individual leaves. While the leaf $\mathrm{CO}_{2}$ assimilation response of $D$ is less than $70 \%$ of $A$ the crop assimilation rate of $D$ is $86 \%$ of the crop productivity of $A$. Therefore to some extent differences in $\mathrm{CO}_{2}$ assimilation rates of individual leaves are lost when leaves are distributed in a crop canopy because assimilation rates of all leaves are assumed equal at low irradiances. Since part of the leaves in the canopy are always at low irradiances and essentially all leaves are subjected to low irradiances at low solar clevations, the $\mathrm{CO}_{2}$ assimilation rates much of the time for many leaves in the canopy have equal productivity irrespective of the differences in their photosynthetic rates under saturating irradiances.

To determine the amount of photosynthate available for seed development, the consumption of hexose by maintenance respiration in the vegetative parts of the crop is estimated. Penning de Vries (1975a) analyzed the glucose requirements for maincenance respiration in supporting the turnover of nitrogenous compounds, maintaining the integrity of membranes, and maintaining ion gradients. The glucose consumption from theoretical considerations was found to be about $40 \mathrm{mg}$ glucose $/ \mathrm{day} / \mathrm{g}$ Iry wt while the experimentally derived data indicated maintenance respiration rates were only about 15 to $25 \mathrm{mg}$ glucose/ lay $/ \mathrm{g}$ dry w't at 20 to $25 \mathrm{C}$. In this analysis we assume a rate of $20 \mathrm{mg}$ glucose/day/g dry $w \mathrm{t}$.

The total rate of glucose consumption by the crop for maintenance respiration is then based on crop dry weight which is in turn estimated from crop leaf area. Total crop leaf area is

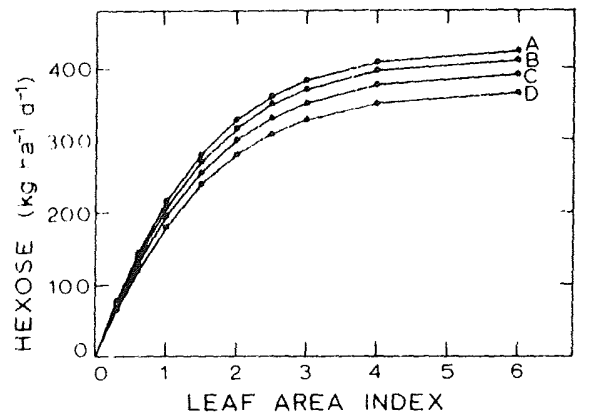

Fig. 2. Simulated gross hexose production of soybean crops at different leaf area indices and with leaves of various $\mathrm{CO}_{2}$ assimitation potentials. Leaf $\mathrm{CO}_{2}$ assimilation potentials were obtained from same data as in Fig. 1 . multiplied by the specific leaf weight of $0.4 \mathrm{~g}$ dry $\mathrm{wt} / \mathrm{dm}^{2}$ leaf area, found for soybeans by Dormhoff and Shibles $(1970)$ to obtain total leaf dry $w t / h a$. We then assume that leaf weight represents only about $1 / 3$ total erop vegetative dry matter. Therefore a crop with a LAI of 4 has an estimated total vegetative dry weight of $4800 \mathrm{~kg} \cdot \mathrm{ha}^{-1}$. Multiplication of the vegetative dry weight by the maintenance respiration rate yields the daily glucose consumption by maintenance respiralion. For example, the crop with a LAI of 4 is estimated to have a maintenance respiration rale of $96 \mathrm{~kg}$ glucose $\cdot \mathrm{ha}^{-1} \cdot$ day $^{-1}$.

The calculated photosynthate available for supporting secel development shown in Fig. 3 is obtained by subiracting main tenance respiration consumption from total fixed hexose. While the crops at the higher LAI are found to have the greater total $\mathrm{CO}_{2}$ fixation, their estimated greater maintenance respiration rates detract from this advantage. The greatest rates of photosynthate available to the seed occur at LAI in the range of 3 to 4 and with the highest leaf $\mathrm{CO}_{2}$ assimilation rates. In fact, the calculated rates of production of available photosynthate under these conditions is quite high and compares favorably with other crops. Only when the LAl falls below 2 is the daily production of glucose appreciably reduced.

The photosynthate remaining after accounting for maintenance respiration is converted to seed biomass by considering the biochemical end-products of soybean seed production. Penning de Vries (1975b) examined the biochemical pathways by which carbohydrate, protein, lipid, and lignin are produced from glucose. He found that the conversion efficiencies were essentially independent of the pathway and the exact subcomponent compositions of the end product. From 1 unit of glucose substrate he found that 0.83 units of carbohydrates, 0.40 units of protein (with nitrate as the nitrogen source), 0.33 units of lipid, or 0.46 units of lignin are produced. The conversion efficiency to protein is unchanged when symbiotic nitrogen fixation is the nitrogen source since the carbohydrate requirements for nitrate reduction and nitrogen fixation are essentially equal (Hardy and Havelka, 1975). These conversion efficiencies are used to calculate the glucose requirements for soybean seed production. Since the soybean seed is assumed to have a dry weight composition of $31 \%$ carbohydrate, $42 \%$ protein, $20 \%$ lipid, $4 \%$ lignin, and $3 \%$ ash; 1 unit of glucose yields 0.47 units of seed biomass. Multiplication of the available photosynthate estimates presented in Fig 3 by 0.47 give a preliminary estimate of the rate of seed biomass growth.

The largest, calculated seed development rate is $148 \mathrm{~kg}$. $\mathrm{ha}^{-1} \cdot \mathrm{d}^{-1}$ for the crop with a LAI of 4 and the highest $\mathrm{CO}_{2}$ assimi lation rate, $A$. This is in agreement with the observed rate of maximum, total dry matter accumulation of $149 \mathrm{~kg} \cdot \mathrm{ha}^{-1} \cdot \mathrm{d}^{-1}$ reported by Hanway and Weber (1971a) in a comparison of eight soybean genotypes. However the rate of seed production by all genotypes in their study was only $108 \mathrm{~kg} \cdot \mathrm{ha}^{-3} \cdot \mathrm{d}^{-1}$ which corresponds more closely with the crop with the lowest leaf $\mathrm{CO}_{2}$ assimilation rate, D. Egli and Leggett (1973) observed a range in seed production rates in two soybean genotypes in a 2 -year study of 78.9 to $133.3 \mathrm{~kg} \cdot \mathrm{ha}^{-1} \cdot \mathrm{d}^{-1}$. Kaplin and Koller (1974) found the rate of seed production among four genotypes to vary from 79.4 to $98.0 \mathrm{~kg} \cdot \mathrm{ha}^{-1} \cdot \mathrm{d}^{-1}$.

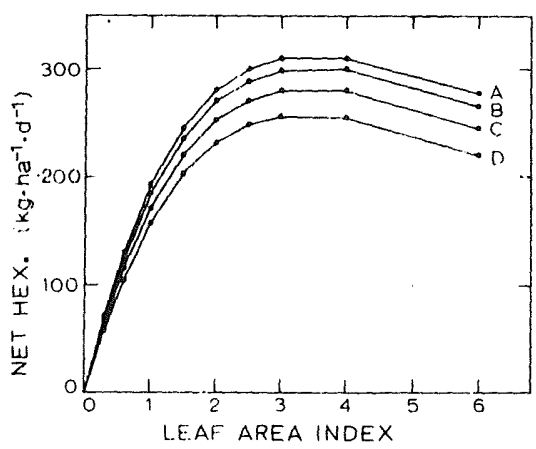

Fig. 3. Simulated net hexose production available for supporting seed production by soybean crops at different leaf area indices and with leaves of various $\mathrm{CO}_{2}$ assimilation potentials. Leaf $\mathrm{CO}_{2}$ assimilation potentials were obtained from same data as in Fig. 1. 


\section{Duration of Seed Development}

Initial estimates of soybean seed yield are obtained by multiplying the rate of seed production by the length of the seed development period. Hanway and Weber (1971a) observed that the length of the period of rapid seed development was restricted to only about 20 to 25 days. Multiplication of the calculated seed production rate of $148 \mathrm{~kg} \cdot \mathrm{ha}^{-1} \cdot \mathrm{d}^{-1}$ by 20 days results in a total soybean seed yield of $2960 \mathrm{~kg} \cdot \mathrm{ha}^{-1}$ which is consistent with experimental observations. However a seed development period restricted to only 20 days seems to be a very limiting characteristic. Lengthening the seed development period by only 5 days increases the calculated soybean yields by $25 \%$. Is the short length of the seed development period the inherent physiological limitation to increased soybean yield? What is the mechanism which appears to restrict the duration of secd growth?

The self-destructive hypothesis (Sinclair and de Wit, 1975) offers a potential explanation to the short period of seed development. Since soybeans cannot apparently obtain sufficient nitrogen at sufficient rates from the soil and/or nodules to sup. port completely high rates of seed growth, we hypothesize that port completely high rates of seed growth, we hypothesize that
nitrogen must be translocated from the vegetative tissue to make up the deficit. Obviously a high rate of nitrogen translocation from the vegetative tissue and the resultant loss of physiological activity are deleterious to sustained high rates of seed growth. In fact, the loss of protein in the vegetative tissues must ultimately result in plant senescence and thereby restrict the duration of the seed development period.

To examine the possible significance of the self-destructive characteristic on limiting the duration of the seed development period, the nitrogen demand of the soybean seed is calculated. The rate of nitrogen demand is estimated by multiplying the rate of biomass production by the relative amount of nitrogen in the seed. Since we assume that nitrogen accounts for about $15 \%$ of the protein weight, soybean seeds are estimated to be $6.3 \%$ nitrogen. Multiplication of the data in Fig. 3 by 0.063 yields the initial estimates of the rates of nitrogen supply required by the developing seed. These data presented in Fig. 4 show that the secds of a soybean crop inay require $9 \mathrm{~kg} \cdot \mathrm{ha}^{-1}$. $d^{-1}$ or more nitrogen. Since we could not find a report of sustained nitrogen supply to soybeans from either the soil or by symbiotic nitrogen fixation being greater than $5 \mathrm{~kg} \cdot \mathrm{ha}^{-1} \cdot \mathrm{d}^{-1}$, we conclude that large quantities of nitrogen must be obtained from an additional source.

The vegetative tissues of soybeans seem to have the capability of translocating substantial quantities of nitrogen to the seed. The data reported by Hanway and Weber (1971b) showed that the quantity of nitrogen lost from tissues during senescence was $3 \%$ or more of the leaf weight and about $2 \%$ of the stem and petiole weight. 'Therefore the translocatable nitrogen from the vegetative tissue of a crop with a LAI of 4 is estimated to be on the order of $130 \mathrm{~kg} \cdot \mathrm{ha}^{-1}$. A steady-state estimate of the duration of the seed development period is calculable from the estimates of total translocatable nitrogen and the nitrogen demand of the seeds. For example, a crop with a total nitrogen demand by the seeds of $9 \mathrm{~kg} \cdot \mathrm{ha}^{-1} \cdot \mathrm{d}^{-1}$ and an external nitrogen

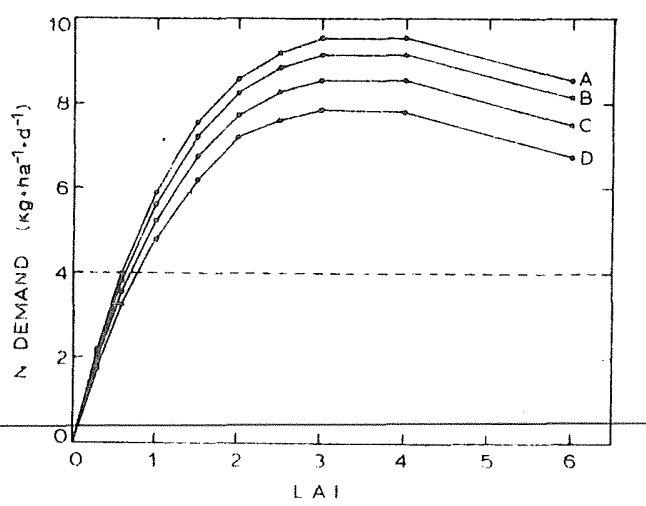

Fig. 4. Steady-state estimate of nitrogen demand of soybean seeds at different leaf area indices and with leaves of various $\mathrm{CO}_{2}$ assimilation potentials. Leaf $\mathrm{CO}_{2}$ assimilation potentials were obtained from same as in Fig. 1 . supply of $4 \mathrm{~kg} \cdot \mathrm{ha}^{-1} \cdot \mathrm{d}^{-1}$ requires $5 \mathrm{~kg} \cdot \mathrm{ha}^{-1} \cdot \mathrm{d}^{-1}$ to be iranslocated from the vegetative lissue Division of $5 \mathrm{~kg} \cdot \mathrm{ha}^{-1} \cdot \mathrm{d}^{-1}$ into the estimate of available nitrogen of $130 \mathrm{~kg} \cdot \mathrm{ha}^{-1}$ shows that the plant would be sclf-destroyed in 26 days. This estimate of the: duration of the seed development period clearly indicates that the self-destructive characteristic may be a significant limita. tion to polential seed yiekl.

However the steady-state calculation of the length of seed development is an inadequate representation of dynamic sced growth for at least two reasons. First, a continued loss in the physiological activily in the vegetative tissue must cocmlually be a consequence of nitrogen translocation. Since a reduction in the rate of photosymbate production probably also resulls from the withdrawal of nitrogen from the leaves, the rate of seed development and consequently the demand for nitrogin by the seed decreases. Second, the steady-state calculation may be optimistic in the estimate of the duration of the secd develop. ment period because the nitrogen sources in these calculations are assumed to be either unreduced nitrate or symbiotically fixed nitrogen. However translocated nitrogen has already been reduced and the consumption of photosynthate to produce protein from a reduced source is much less. Penning de Vrics $(1975 \mathrm{~b})$ estimated that one unit of glucose yields 0.62 units of protein when the nitrogen source was ammonium. As a result, seed development supported by translocated nitrogen is estimated to yield 0.57 units of biomass/unit of glucose. Since the sced productivity is higher per unit of photosynthate with translocated nitrogen, the demand for nitrogen is proportionally greater and further shortens the seed development period.

\section{Model}

To account for the dynamic features of the carbon and ritrogen balance on soybean seed development a simple model written in the Continuous Systems Modeling Program (CSMP) language is developed. One large uncertainty in developing this model is the simulation of the effect of nitrogen translocation on the loss of physiological activity in the vegetative tissues. We assume that the decrease in photosynthate production with the loss of nitrogen is not linear because a portion of nitongen available in the vegetative tissue for translocation an be presumably lost without any serious effect on photosynthesis. In addition, initial destruction of proteins may result in greater efficiency of the remaining proteins suggesting a minimal decrease in photosynthate production at the onset of nitrogen translocation. Since precise data are not available on the rela. tionship between nitrogen translocation and loss of photosynthate activity in soybeans, we simulate this process by causing the nitrogen translocation to destroy increments of leaf area and a proportional amount of petioles and stems. Therefore we begin the simulation with a defined amount of leaf area and incrementally destroy the plant in proportion to the rate of nitrogen translocation. As shown in Fig. 3, a decrease in leaf area provides a simple feedback mechanism for the hypothesized nonlinear effect of nitrogen translocation. The production of photosynthate is not limited until the LAI falls below 3.0 and

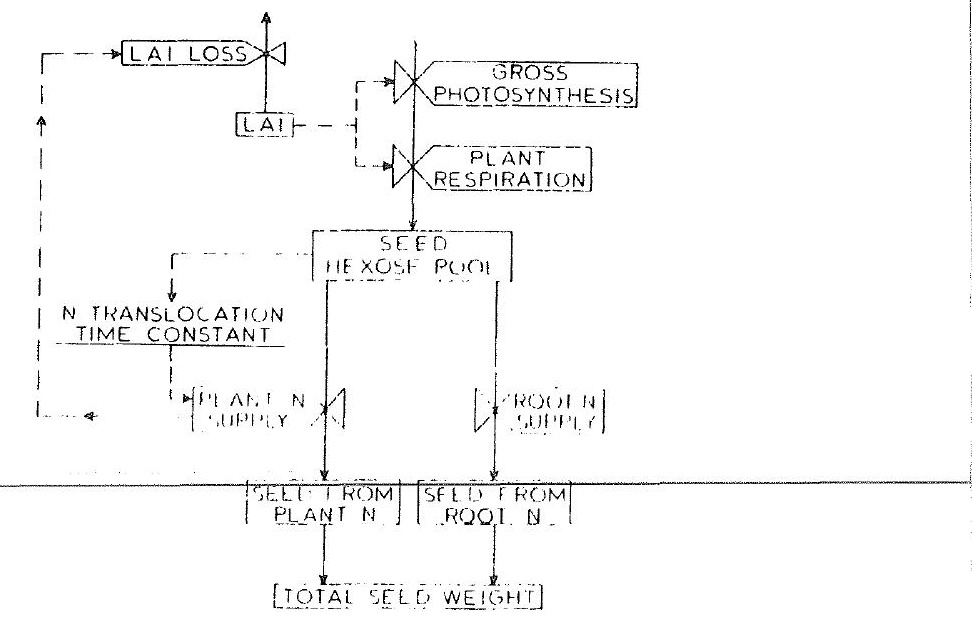

Fig. 5. Flow diagram of CSMP model of soybean seen production. 


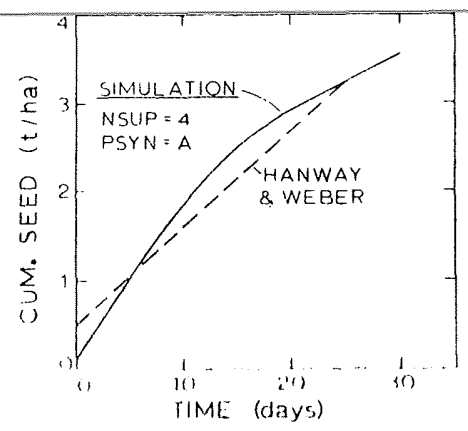

Fig. 6. Simulated increase in cumulative soybean seed weight with time for a crop with leaf $\mathrm{CO}_{2}$ assimilation potentials of unshaded leaves, $A$, and a root nitrogen supply of 4 $\mathrm{kg} \cdot \mathrm{ha}^{-1} \cdot \mathrm{d}^{-1}$. The experimental observations of Hanway and Weber (1971a) are presented as the dashed line.

then the available photosynthate drops slowly until a LAI of about 1.5 is reached.

The flow diagram for the soybean seed production model is shown in Fig. 5. The initial step in the program is to calculate the rate of photosynthesis and maintenance respiration from the current LAI. The net photosynthate is placed in a hexose pool available solely for supporting seed production. The nitrogen supplied from the root either by symbiotic nitrogen fixation or sssimilation of nitrate from the soil is fixed immediately into seed material. Since the energy requirements for nitrogen fixation and nitrate assimilation are approximately equal (Hardy and Havelka, 1975), we do not attempt to discriminate between these two processes. The remaining photosynthate is converted to seed material with the efficiency cal culated for an ammonium source and at a rate determined by the rate of nitrogen translocation from the vegetative plant. The rate of nitrogen translocation is in turn dependent on the size of the hexose pool and the time constant of translocation. Since the simulations were fairly insensitive to the magnitude of the time constant, it was held at a value of 2 days for all simulations.

The LAI of the plant is reduced in proportion to the nitrogen translocated to the seed. We assume that the leaves are $1 / 3$ the biomass of the tissue and their nitrogen loss is $4 \%$ of their total weight. The remaining $2 / 3$ vegetative biomass is assumed to lose $2 \%$ of their total weight as nitrogen. Therefore half the nitrogen supplied to the seed is derived fom leaves while the other half cones from the remaining vegetative tissue. The destroyed biomass of leaves is readily calculated from the estimate of nitrogen translocdted to the seed. To convert the biomass destrucion of leaves back to LAI, the specific leaf w'eight of soybean leaves of $0.4 \mathrm{~g}$ dry $w t / \mathrm{dm}^{2}$ observed by Dornhoff and Shibles $(1970\rangle$ is used.

The simulations are allowed to proceed until the available photosynthate pool for seed development is depleted. That is, when the steady-state condition is achieved, where nitrogen is no longer translocated from the vegetative plant, the simulations are stopped. Generally the termination occurs after the LAI is well below 1.0 indicating considerable senescence of the plant and a low rate of seed growth. No simulations are allowed to continue longer than 40 days to prevent unrealistically long seed development periods. That is, other influences are assumed to bring the seeds to maturity at 40 days if the selfdestructive characteristic has not already terminated growth.

\section{RESULTS AND DISCUSSION}

One of the greatest difficulties in simulating soybean secd production appears to be estimation of the nitrogen supply from the root by either nitrogen fixation or by nitrate assimilation. While we fully expect significant feedback loops between photosynthate availability and nitrogen assimilation, no data are available to simulate these feedbacks quantitatively. Nevertheless our objective is to examine the potential significance of the self-destructive hypothesis and not

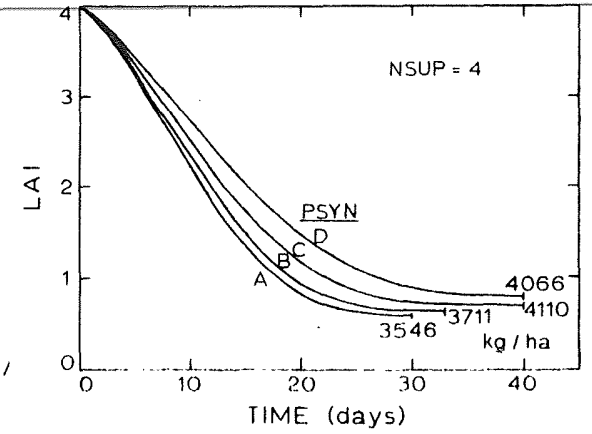

Fig. 7. Simulated changes in leaf area indices with time for soybean crops with an initial leaf area index of 4, a 4 $\mathrm{kg} \cdot \mathrm{ha}^{-1} \cdot \mathrm{d}^{-1}$ root nitrogen supply, and leaves of various $\mathrm{CO}_{2}$ assimilation potentials. Final seed yields are presented in lower, right-hand portion of figure.

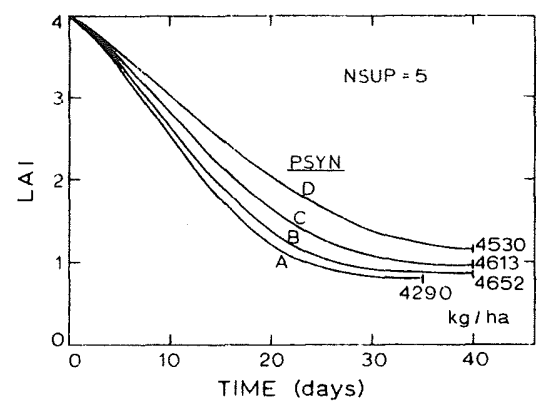

Fig. 8. Simulated changes in leaf area indices with time for soybean crops with an initial leaf area index of 4 , a 5 $\mathrm{kg} \cdot \mathrm{ha}^{-1} \cdot \mathrm{d}^{-1}$ root nitrogen supply, and leaves of various $\mathrm{CO}_{2}$ assimilation potentials. Final seed yields are presented in lower, right-hand portion of figure.

necessarily to mimic precisely soybean seed growth. A worst case test of the self-destructive hypothesis can be made by setting the nitrogen supply at a constant, high rate. Since nitrogen assimilation in soybean plants decreases at the end of seed development, a constant nitrogen supply rate will overestimate nitrogen availability, decrease the demand for nitrogen translocation, and prolong the simulated duration of seed development. The potential significance of the self-destructive characteristic will, therefore, be minimized in the initial simulations. In addition, simulations which initially allow nitrogen supply rate to be independent of photosynthate availability allow the effects of varying photosynthate and nitrogen assimilation to be analyzed separately.

The initial simulation is performed with a soybean crop with a constant root nitrogen supply of 4 $\mathrm{kg} \cdot \mathrm{ha}^{-1} \cdot \mathrm{d}^{-1}$ which is a high rate and surely results in a much exaggerated nitrogen supply during the latter stages of seed development. The crop was given an initial LAI of 4 and the highest rate of leaf $\mathrm{CO}_{2}$ assimilation, $A$. The simulated change in cumulative seed weight with time and the observations of Hanway and Weber (197la) are plotted in Fig. 6. While the simulated accumulation of seed biomass is curvilinear in contrast to the linear change observed experimentally, the self-destructive characteristic as incorporated into the model terminated seed development at 30 days and gave only a slightly larger seed 


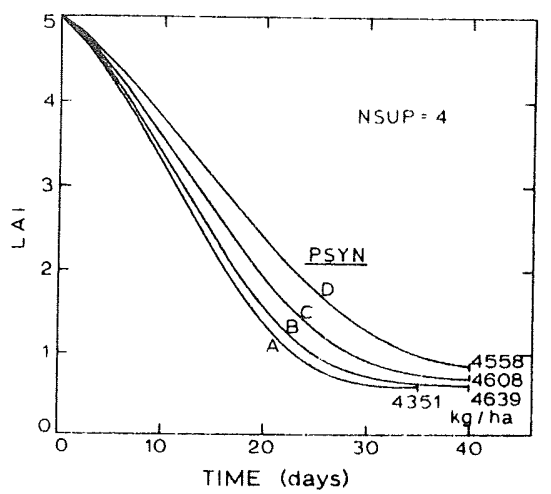

Fig. 9. Simulated changes in leaf area indices with time for soybean crops with an initial leaf area index of 5, a 4 $\mathrm{kg} \cdot \mathrm{ha}^{-1} \cdot \mathrm{d}^{-1}$ root nitrogen supply, and leaves of various $\mathrm{CO}_{2}$ assimilation potentials. Final seed yields are presented in lower, right-hand portion of figure.

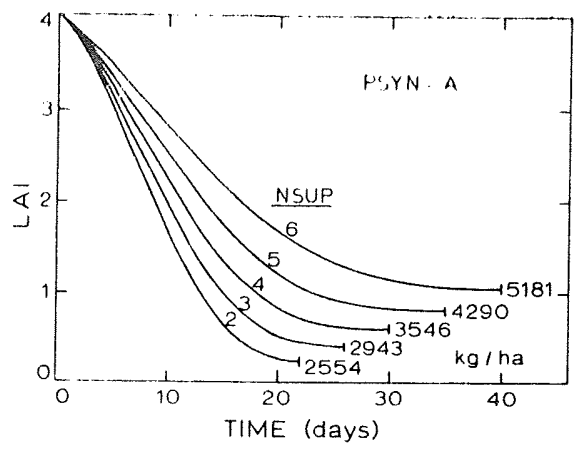

Fig. 10. Simulated changes in leaf area indices with time for soybean crops with an initial leaf area index of 4 , leaves hav ing a $\mathrm{CO}_{2}$ assimilation potential of an unshaded leaf (A), and various rates of root nitrogen supply. Final seed yields are presented in lower, righthand portion of figure.

yield even though the nitrogen supply was held constant at $4 \mathrm{~kg} \cdot \mathrm{ha}^{-1} \cdot \mathrm{day}^{-1}$. This simulation indicates that the expression of the nitrogen balance through the self-destructive phenomenon can be an important potential limitation to soybean seed yields.

Additional simulations are performed to determine the relative effect of several crop variables on seed yield. Surprisingly alterations in the initial leaf area indices and the rates of nitrogen supply from the roots have only small effects on the rate of seed production shown in Fig. 6. However the duration of seed develop. ment changed a great deal in response to these variables. These results, again, confirm that soybean yields seem to be limited more by the length of the seed development period than by the rate of seed development.

To show more clearly the effect of variations in the state variables in these simulations, the LAI of the crop is plotted against time. The results of simulations with the initial L.AI fixed at 4 , the root nitrogen supply set at $4 \mathrm{~kg} \cdot h_{\mathrm{a}^{-1}} \cdot \mathrm{d}^{-1}$, and varying leaf $\mathrm{CO}_{2}$ assimilation rates are plotted in Fig. 7. These results show that increased photosynthetic potential was, in fact, detrimental to the duration of the seed development period and final seed yield. The detrimental effect of increased photosynthesis occurs because the direct response to greater photosynthate productivity in this simple model is an increase in the pool of hexose available for seed development. A larger hexose pool causes a greater demand for nitrogen translocation and aggrevates to a greater extent the self-destruction characteristic. The two crops with the highest photosynthetic rates, $A$ and $B$, are not able to sustain seed growth through the 40 days alloted in these simulations. These results also show a relative stability in final seed yield over the range of simulated photo. synthetic potentials and suggest that if nitrogen assimilation rates are unchanged improvements only in photosynthetic activity of soybean leaves will not pro. duce large increases in seed yield.

The above simulations are repeated but the rate of constant root nitrogen supply is increased to $5 \mathrm{~kg}$. $\mathrm{ha}^{-1} \cdot \mathrm{d}^{-1}$. The results, plotted in Fig. 8, show that the enhanced rate of nitrogen supply greatly increases final seed yield. As expected the greater supply of nitrogen from the root decreases the demand on the vegetative plant tissues and the rate of self-destruction is reduced. Only the crop with the highest photosyn thetic activity has its seed development terminated before the 40 day time limit. The importince of the nitrogen availability limiting the length of the seed development period and final seed yield is reemphasized in the simulations where the initial LAI is raised to 5 and the nitrogen supply rate from the root is left at $4 \mathrm{~kg} \cdot \mathrm{ha}^{1-} \cdot \mathrm{d}^{-1}$. In these comparisons a high rate of nitrogen translocation from the vegetative plant is still required but the reservoir of nitrogen within the plant is larger. As shown in Fig. 9, the higher initial LAI allows all but the crop with the greatest photosynthetic activity to avoid self-destruction during the 40 day seed development period.

To complete the initial analysis of the potential effect of nitrogen on soybean productivity, simulations are done using the highest photosynthetic rate, $\mathrm{A}$, and an initial LAI of 4 while varying the rate of root nitrogen supply from 2 to $6 \mathrm{~kg} \cdot \mathrm{ha}^{-1} \cdot \mathrm{d}^{-1}$. The results of these simulations, presented in Fig. 10, clearly show the direct correlation between the rate of nitrogen supply and the duration of the seed development period and final seed yield. The assumptions used in these simulations demonstrate the potential significance of the soybean nitrogen balance on restricting increased seed yields. Substantial increases in seed yield are achieved in these simulations only by in. creasing the availability of nitrogen to the developing seed.

While the preceding simulations clearly indicate the importance of the self-destructive hypothesis in limiting soybean yields, the question still remains whether this approach is valid to mimic soybean production. Obviously in a predictive model the nitrogen supply rate from the roots cannot be held constant and is almost surely dependent on the availability of photosynthate. To examine the potential of the self-destructive concept in mimicking soybean seed production, we set the nitrogen supply rate equal to a constant fraction of the daily net photosynthate production. Simulations of varying ratios of nitrogen supply to net photosynthate production show little difference in the rate of seed growth but very marked differences in the duration of the seed development period. As anti- 


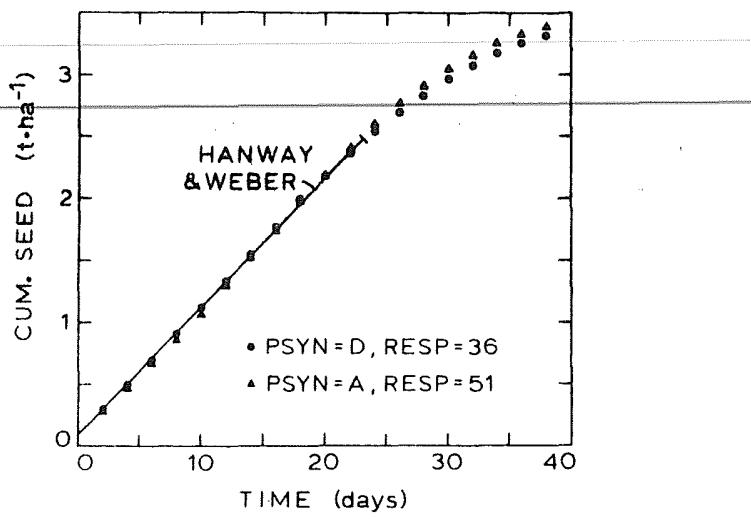

Fig. 11. Simulated increase in cumulative soybean seed weight with time for a crop with leaf $\mathrm{CO}_{2}$ assimilation potentials of unshaded leaves, $A$, and a maintenance respiration rate of $51 \mathrm{mg}$ glucose/gm dry wt and for a crop with leaf $\mathrm{CO}_{3}$ assimilation potentials of $70 \%$ shaded leaves $D$, and a main. lation potentials of $70 \%$ shaded leaves $D$, and a main-
tenance respiration rate of $36 \mathrm{mg}$ glucose $/ \mathrm{gm}$ dry wt. Root nitrogen supply was equal to 0.015 of the calculated net photo. synthesis rate. The experimental observations of Hanway and Weber (1971a) are presented as the dashed line.

cipated in Fig. 10, increased nitrogen supply rates lengthen the period of seed development and result in substantial yield increases.

To mimic soybean seed production, we set the supply rate of nitrogen equal to 0.015 of the net photosynthate production rate. Therefore, a $200 \mathrm{~kg} \cdot \mathrm{ha}^{-1} \cdot \mathrm{day}^{-1}$ photosynthesis rate results in a $3 \mathrm{~kg} \cdot \mathrm{ha}^{-1} \cdot \mathrm{day}^{-1} \mathrm{ni}$ trogen supply rate. The inclusion of the variable nitrogen supply rate dependent on photosynthesis results in a nearly linear increase in cumulative seed weight through the seed development period. While the rate of seed weight increase in the initial simulations did not match the observations of Hanway and Weber (1971a), the rate of seed weight increase is easily adjusted in the model by increasing the maintenance respiration rate to a value greater than the $20 \mathrm{mg}$ glucose per day per $g$ dry weight originally assumed. The simulations shown in Fig. 11 for the crop with the highest, $A$, and the lowest, D, photosynthetic rates agree well with the experimental data when maintenance respiration rates are increased to 51 and $36 \mathrm{mg}$ glucose/day/g dry wt, respectively. These values for maintenance respiration more closely approximated the $40 \mathrm{mg}$ glucose/day/g dry wt theoretically derived by Penning de Vries (1975a). It is also possible to achieve the same simulation results while holding maintenance respiration constant at a low value by decreasing the leaf weight fraction of total crop weight.

In any event, the inclusion of a variable nitrogen supply rate which is related to the physiological activity of the plant and an adjustment of the photosynthate availability by increasing maintenance respiration rate results in very close agreement with the data of Hanway and Weber (1971a). These additional simulations confirmed the crucial role of nitrogen supply rate and the duration of seed development on soybean yields. Reasonable agreement has also been obtained with this model when compared with seed yields of horse bean cultivars (Vicia sp.) in the Netherlands (Dantuma, IBS, Wageningen, personal communications) since the simulations and experimental ob- servations result in similar decreases in seed yields as the percent protein in the seed increases.

\section{CONCLUSIONS}

The initial simulations designed to study the selfdestructive hypothesis clearly demonstrate the potential significance of nitrogen availability in limiting soybean seed yields. The main source of variability in seed yield is the duration of the seed development period. Either an increase in nitrogen supply rate from the roots or an increase in stored nitrogen within the vegetative plant lengthens the seed development period and increases seed yields. Interestingly an increase in photosynthetic rates, without a concomitant increase in nitrogen supply rates, results in decreased seed yields because the added photosynthate only causes greater nitrogen demand and translocation to the seeds.

The simulations designed to more closely mimic soybean production also indicate the importance of the nitrogen supply rate on seed yields. These simulations show that strategies for lengthening the duration of the seed development period are crucial for increasing soybean seed yields. The most direct method for increasing the length of seed development is to increase the proportion of photosynthate being allocated to support new nitrogen assimilation. Consequently, increasing plant photosynthesis under conditions which allow a greater proportion of photosynthate to be used to support nitrogen assimilation would be expected to increase seed yields.

\section{LITERATURE CITED}

Blad, B. L., and D. G. Baker. 1972. Orientation and distribution of leaves within soybean canopies. Agron. J. 64:26-29.

Bowes, G., W. L. Ogren, and R. H. Hageman. 1972. Light saturation, photosynthesis rate, RuDP carboxylase activity, and specific leaf weight in soybeans grown under different light intensities. Crop Sci. 12:77-79.

Curtis, P. E., W. L. Ogren, and R. H. Hageman. 1969. Varietal effects in soybean photosynthesis and photorespiration. Crop Sci. 9:323-327.

Dornhoff, G. M., and R. M. Shibles, 1970. Varietal differences in net photosynthesis of soybean leaves. Crop Sci. 10:42-45.

Dreger, R. H., W. A. Brun, and R. L. Cooper. 1969. Effect of genotype on the photosynthetic rate of soybean (Glycine max (L.) Merr.) Crop Sci. 9:429-431.

Egli, D. B., and J. E. Leggett. 1973. Dry matter accumulation patterns in determinate and indeterminate soybeans. Crop Sci. 18:220-222.

Goudriaan, J. 1973. A calculative model and descriptive formulas for the extinction and reflection of radiation in leaf canopies. Symp. Proc. of Sun in the Service of Mankind. Paris.

Hanway, J. J., and C. R. Weber. 1971a. Dry matter accumulation in eight soybean (Glycine max (L.) Merrill) varieties. Agron. J. $63: 227-230$.

- and - $1971 \mathrm{~b}, \mathrm{~N}, \mathrm{P}$, and $\mathrm{K}$ percentages in soybean (Glycine $\max$ (L.) Merrill) plant parts. Agron. J. 63:286-290.

Hardy, R. W. F., and U. D. Havelka. 1975. Nitrogen fixation research: A key to world food? Science 188:633-643.

Kaplan, S. L., and H. R. Koller. 1974. Variation among soybean cultivars in seed growth rate during the linear phase of seed growth. Crop Sci. 14:613-614.

Penning de V'ries, F. W. T. 1975a. 'The cost of maintenance processes in plant cells. Ann. Bot. (London) 39:77-92. 1975b. Use of assimilates in higher plants. In J. P. Cooper (ed.). Photosynthesis and productivity in different environments. Cambridge University Press.

Sinclair, T. R., and C. T. de Wit. 1975. Comparative analysis of photosynthate and nitrogen requirements in the production of seeds by various crops. Science 189:565-567. 
